\title{
Comparison of Size and Geography of Airborne Tungsten Particles in Fallon, Nevada, and Sweet Home, Oregon, with Implications for Public Health
}

\author{
Paul R. Sheppard, ${ }^{1}$ Brian J. Bierman, ${ }^{2}$ Kent Rhodes, ${ }^{2}$ Gary Ridenour, ${ }^{3}$ and Mark L. Witten ${ }^{4}$ \\ ${ }^{1}$ Laboratory of Tree-Ring Research, University of Arizona, Tucson, Az 85721, USA \\ ${ }^{2}$ McCrone Associates, Inc., 850 Pasquinelli Drive, Westmont, IL 60559, USA \\ ${ }^{3} 625$ W. Williams, Suite B, Fallon, Nevada 89406, USA \\ ${ }^{4}$ Odyssey Research Institute, 7032 East Rosewood Street, Tucson, AZ 85710, USA
}

Correspondence should be addressed to Paul R. Sheppard, sheppard@ltrr.arizona.edu

Received 7 October 2011; Accepted 21 November 2011

Academic Editor: Kelishadi Roya

Copyright ( $) 2012$ Paul R. Sheppard et al. This is an open access article distributed under the Creative Commons Attribution License, which permits unrestricted use, distribution, and reproduction in any medium, provided the original work is properly cited.

\begin{abstract}
To improve understanding of possible connections between airborne tungsten and public health, size and geography of airborne tungsten particles collected in Fallon, Nevada, and Sweet Home, Oregon, were compared. Both towns have industrial tungsten facilities, but only Fallon has experienced a cluster of childhood leukemia. Fallon and Sweet Home are similar to one another by their particles of airborne tungsten being generally small in size. Meteorologically, much, if not most, of residential Fallon is downwind of its hard metal facility for at least some fraction of time at the annual scale, whereas little of residential Sweet Home is downwind of its tungsten facility. Geographically, most Fallon residents potentially spend time daily within an environment containing elevated levels of airborne tungsten. In contrast, few Sweet Home residents potentially spend time daily within an airborne environment with elevated levels of airborne tungsten. Although it cannot be concluded from environmental data alone that elevated airborne tungsten causes childhood leukemia, the lack of excessive cancer in Sweet Home cannot logically be used to dismiss the possibility of airborne tungsten as a factor in the cluster of childhood leukemia in Fallon. Detailed modeling of all variables affecting airborne loadings of heavy metals would be needed to legitimately compare human exposures to airborne tungsten in Fallon and Sweet Home.
\end{abstract}

\section{Introduction}

Size and geography of airborne tungsten particles collected in Fallon, Nevada, and Sweet Home, Oregon (Figure 1), were compared as part of ongoing research on the cooccurrence of airborne tungsten and a cluster of childhood leukemia in Fallon. Fallon experienced a cluster of childhood leukemia beginning in 1997 [3], with the last case announced in 2004 [4]. Although the cluster is thought to have abated [5], at least one additional case of childhood leukemia has occurred in Fallon since 2004 [6]. Given Fallon's pediatric population of about 2500 children up to 19 years in age [1], and a national expected rate of childhood leukemia of 4.1 cases per 100,000 children up to 19 years in age per year [7], the expected rate of childhood leukemia for Fallon should be only one case every ten years.
This cluster, deemed "one of the most unique ... ever reported" [8], prompted extensive research in an effort to find a cause. Among other findings, multiple lines of evidence have shown that Fallon has elevated levels of airborne tungsten and cobalt [9-13].

Although Nevada is naturally rich in tungsten minerals, including geologically [14] and hydrologically [15, 16], Fallon also has a potential anthropogenic source of airborne tungsten. An industrial facility specializing in hard-metal metallurgy, which uses tungsten carbide and cobalt to produce tool materials [17], is located within Fallon. This hard-metal facility was named by the Nevada State Health Division as a candidate source of tungsten in Fallon [18]. Morphological and chemical characteristics of airborne tungsten particles in Fallon indicate that they are anthropogenic in origin, not natural [19]. 
TABLe 1: Geographical comparison between Fallon and Sweet Home.

\begin{tabular}{lcccc}
\hline Community & Population $^{\mathrm{a}}$ & No. of employees in tungsten facility & Annual temperature $\left({ }^{\circ} \mathrm{C}\right)$ & Annual precipitation $(\mathrm{mm})$ \\
\hline Fallon & 7,536 & $\sim 100^{\mathrm{b}}$ & 11.2 & 135 \\
Sweet Home & 8,016 & $11^{\mathrm{c}}$ & 11.6 & 1,397 \\
\hline
\end{tabular}

${ }^{\mathrm{a}}$ From [1].

${ }^{\mathrm{b}}$ From [2].

'Personal communication with facility manager.

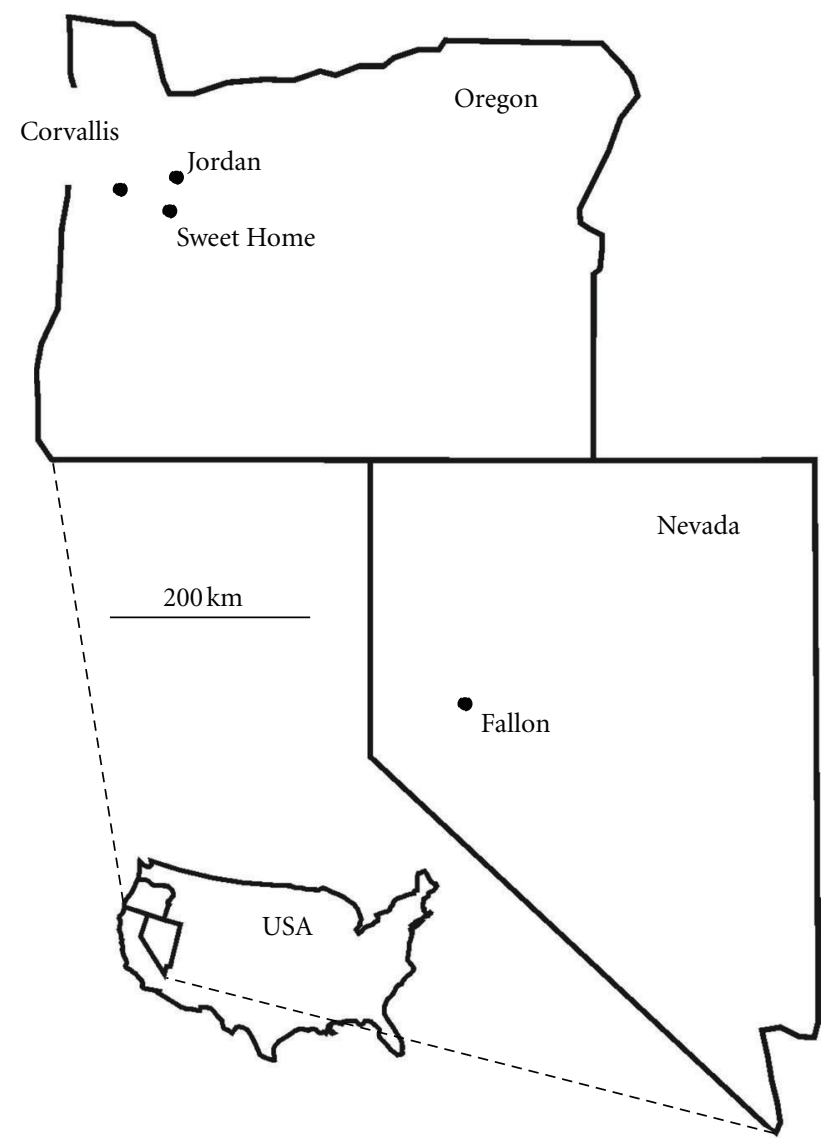

Figure 1: Regional map of Nevada and Oregon showing the location of Fallon and Sweet Home and weather stations of Oregon.

To improve understanding of possible connections between airborne tungsten and public health in Fallon, it would be useful to replicate this research in other small communities that have an industrial source of airborne tungsten in order to compare airborne tungsten and rates of cancer across towns. Sweet Home, Oregon, is another town that has an industrial source of airborne tungsten. As a first step in comparing Sweet Home to Fallon, environmental monitoring techniques used in Fallon were employed in Sweet Home [20]. Elevated airborne tungsten was accurately indentified near the known industrial facility in Sweet Home relative to outlying forests and to the outskirts of Sweet Home.

To our knowledge, Sweet Home has not experienced increased rates of cancer. This prompts a question about airborne tungsten and public health: if exposure to airborne tungsten and/or cobalt particles caused, or even contributed to, the cluster of childhood leukemia in Fallon, then why is there not an increased rate of childhood leukemia in Sweet Home? One possible answer to this question could be that tungsten particles and/or geographical traits differ between Fallon and Sweet Home such that actual human exposure to airborne tungsten differs between these towns. Accordingly, the objectives of this research were (a) to measure and characterize the size of airborne tungsten particles of both towns, (b) to analyze spatial patterns of dispersal of airborne tungsten of both towns, and (c) to compare potential human exposure to airborne tungsten between Fallon and Sweet Home.

\section{Materials and Methods}

2.1. Fallon and Sweet Home. Fallon and Sweet Home are similar in that both are rural towns with small populations of about 8,000 people (Table 1), and both towns have industrial facilities that process or otherwise use fine tungsten particles. Based on number of employees, the Fallon tungsten facility is larger than that of Sweet Home. Fallon and Sweet Home have similar annual mean temperatures $\left(\sim 11^{\circ} \mathrm{C}\right)$, but Sweet Home receives 10 times more rainfall than Fallon on average.

2.2. Air Sampling. In March and November, 2004, airborne dust was collected within Fallon using portable, high-volume particulate air samplers [9]. Weather during these collection periods was generally sunny and windy in March and rainy in November. The filter type was glass-fiber, a common medium for high-volume sampling of airborne particulates [21, 22 ]. Filters were $510 \mu \mathrm{m}$ thick and had up to $99.99 \%$ retention for particles down to sub- $\mu \mathrm{m}$ sizes [23]. In May, 2005, airborne dust was collected within Sweet Home using the same equipment used in Fallon [20]. Weather during this collection period was generally sunny and calm.

For the particle size part of this research, three filters were selected from both Fallon and Sweet Home for further measurement and analysis. The filters were selected to optimize a transect of distance from their respective industrial tungsten facilities.

2.3. Additional Sampling in Sweet Home. Two additional samples of tungsten-laden dust were collected in 2011 in Sweet Home. One, dust was collected from the powder drum itself, which was not the actual product of the industrial facility but rather the fine waste that results from its processing. This allowed assessment of tungsten particles that 


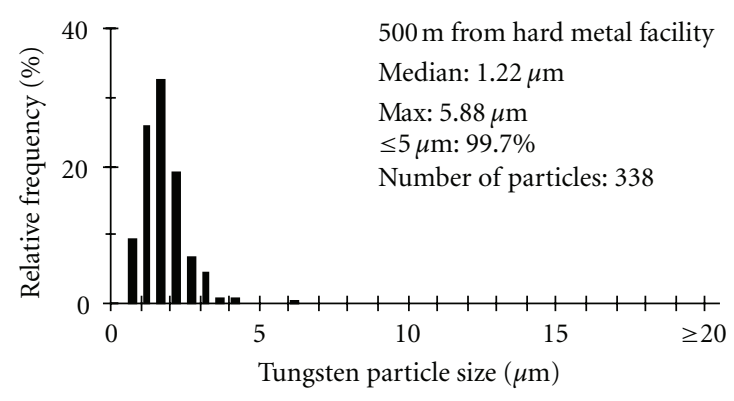

(a) Fallon air filter 1

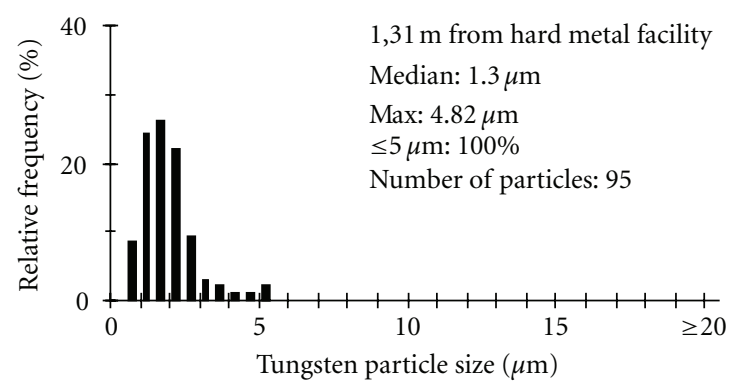

(b) Fallon air filter 2

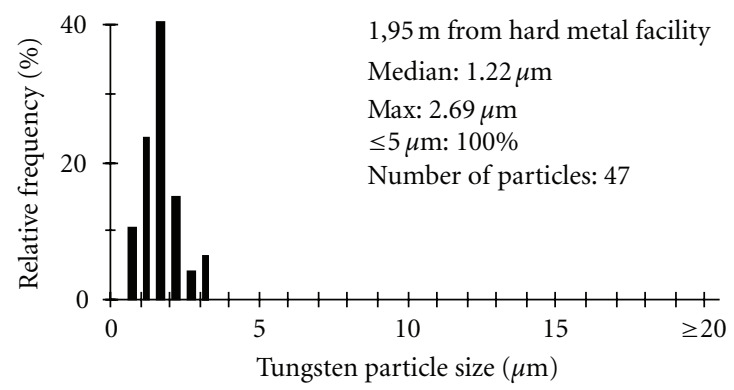

(c) Fallon air filter 3

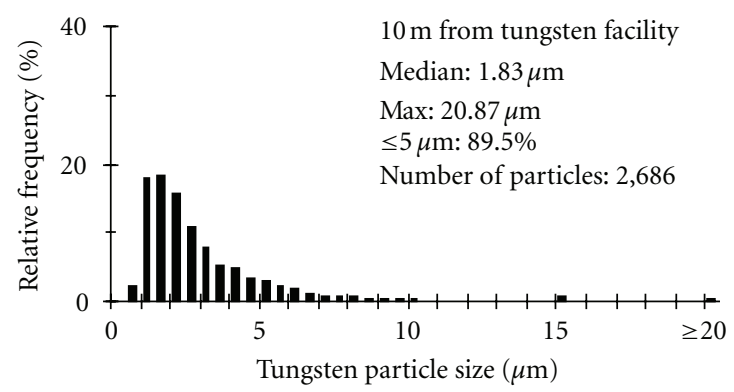

(d) Sweet Home air filter 1

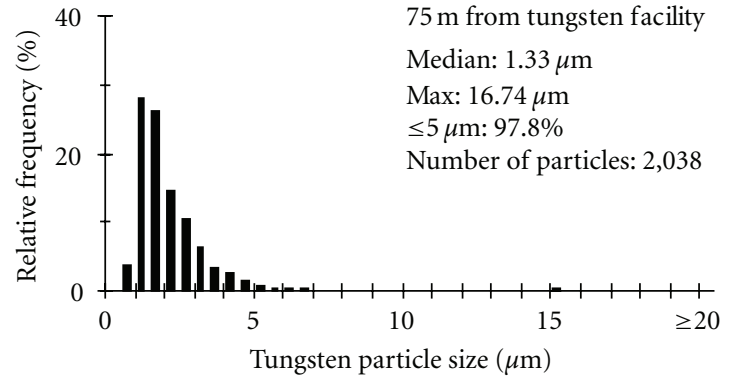

(e) Sweet Home air filter 2

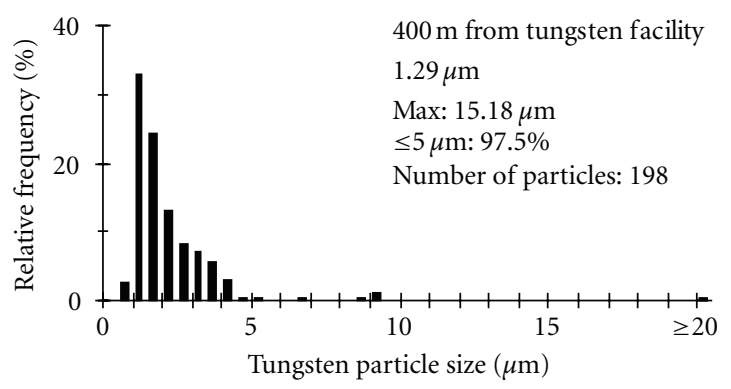

(f) Sweet Home air filter 3

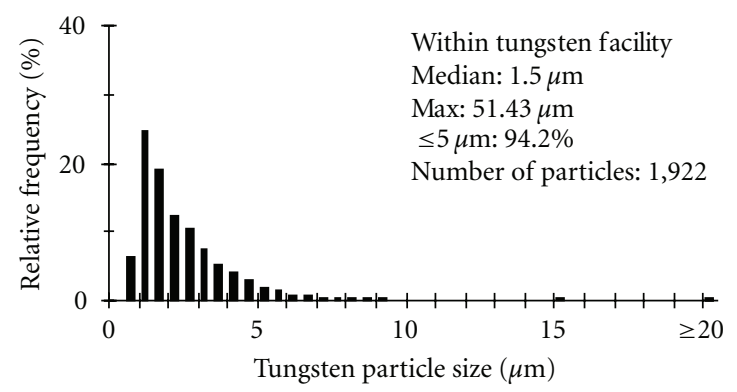

(g) Sweet Home powder drum

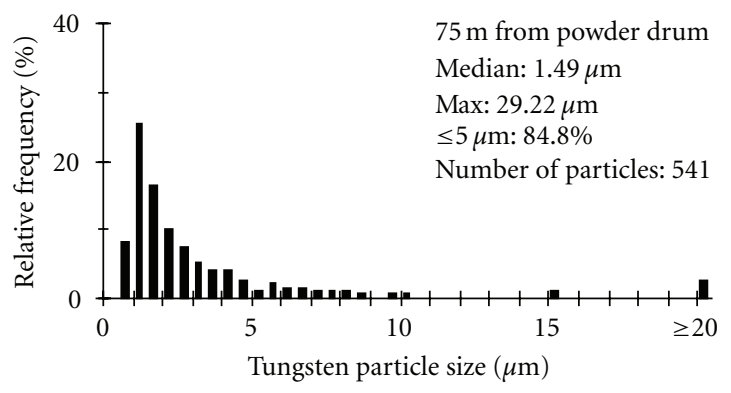

(h) Sweet Home surface dust

Figure 2: Frequency histograms of tungsten particles by size for each sample analyzed from Fallon and Sweet Home.

result from the production process. Two, surface dust was swept up from pavement just east of the facility. This allowed assessment of airborne tungsten particles that drift out of the building but do not travel far from the source.

2.4. Isolation of Tungsten Particles. To remove the collected particulate matter from the glass-fiber filters for microanalysis, a $20 \mathrm{~cm}^{2}$ portion of each filter was placed into its own $50 \mathrm{~mL}$ plastic centrifuge tube with approximately $10 \mathrm{~mL}$ of ethanol. The tubes were sonicated for 20 minutes to dislodge the particles, and then the filter pieces were removed from the tubes and saved. Approximately $50 \mathrm{mg}$ of the powder drum and surface dust samples was placed into their own centrifuge tubes, again with approximately $10 \mathrm{~mL}$ of ethanol.

Fifteen $\mathrm{mL}$ of methyl iodide was added to the centrifuge tubes, and the samples were centrifuged for 10 minutes at $2000 \mathrm{rpm}$. The ethanol layer was pipetted off and saved. The bottom methyl iodide layer was filtered on 25-millimeter polyester membrane filters and mounted onto aluminum stubs 


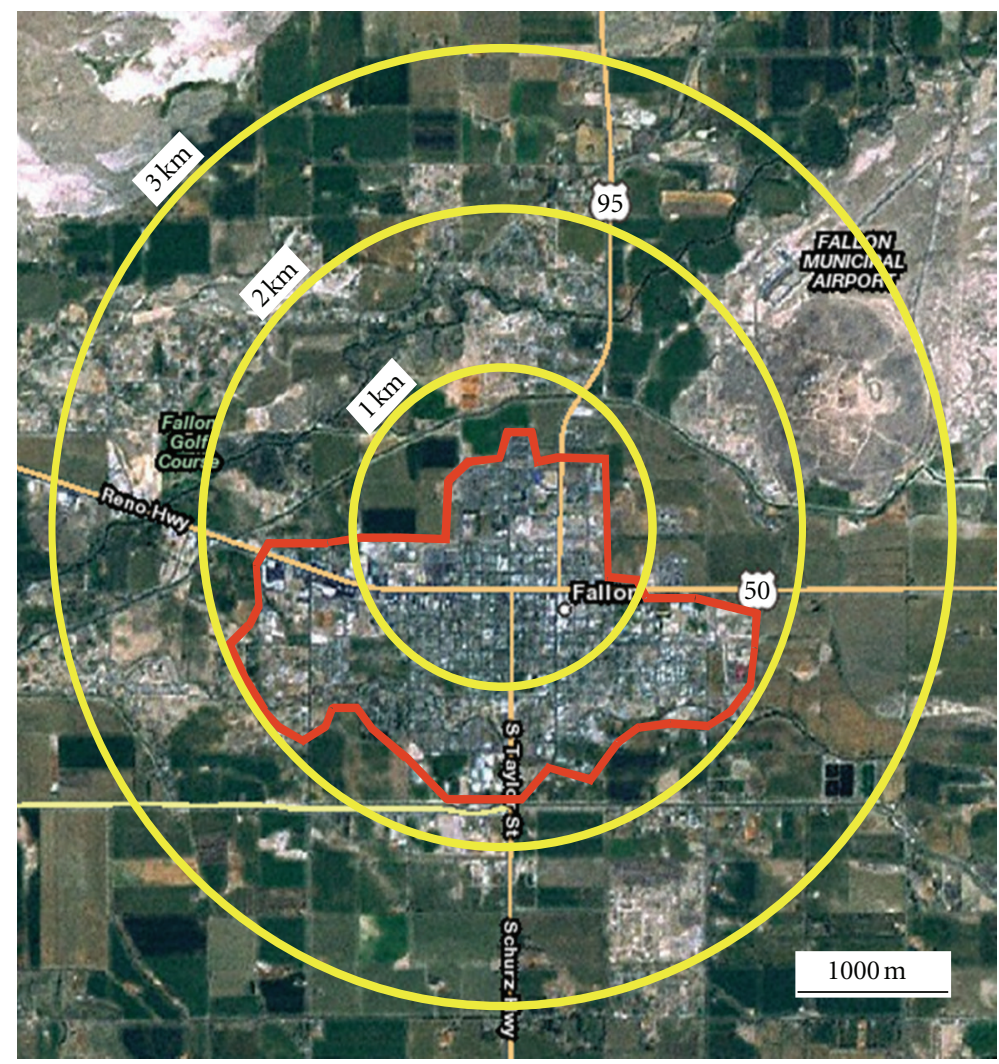

FIgURE 3: Aerial view of Fallon, Nevada, with $1 \mathrm{~km}$ distances centered on the hard metal facility. The red boundary marks the limit of residential Fallon.

for automated analysis. This method recovers a representative sample for particle sizing and chemical analysis and has worked specifically with tungsten particles in prior work [19].

2.5. Automated Particle Analysis. Samples were analyzed using an ASPEX 3025 personal scanning electron microscope (PSEM) utilizing energy dispersive X-ray spectrometry (EDS) and ASPEX's automated feature analysis (AFA) software. This system and software located, counted, measured, and quantitatively analyzed particles in fully automated mode. Particles containing less than 80\% tungsten were culled out of the data set. Frequency histograms plotting the size of tungsten particles were generated, and images of representative particles were collected. Calibration was performed using (1) a certified tungsten standard from Geller Microanalysis Laboratory for tungsten quantification, (2) a copper standard for energy scaling, and (3) a commercial standard (PGS) from Aspex LLC for particle sizing.

2.6. Geographical Analysis. Aerial photos of both towns were labeled with limits of residential areas, locations of respective industrial tungsten facilities, and circles of elevated levels of airborne tungsten. Prevailing wind directions of both towns were illustrated with wind rose diagrams using data from nearby weather stations.

\section{Results and Discussion}

3.1. Tungsten Particles from Air Filters. The size distributions of tungsten particles are similar across all six air filters from both towns. Median sizes of tungsten particles across all air filters range from 1.22 to $1.83 \mu \mathrm{m}$ in diameter (Figures $2(\mathrm{a})-2(\mathrm{f}))$. This size class $(<2.1 \mu \mathrm{m})$ is typical for airborne particulates of heavy metals [24]. The particulate size class of 1 to $2 \mu \mathrm{m}$ in diameter is also considered seriously threatening to human health [25]. Additionally, the vast majority of tungsten particles isolated from both towns air filters were below $5 \mu \mathrm{m}$ in size (Figures 2(a)-2(f)). The Sweet Home filters also contained tungsten particles considerably larger than the median size, ranging up to $21 \mu \mathrm{m}$ in diameter, but very particles were this large.

\subsection{Tungsten Particles from the Powder Drum and Surface} Dust in Sweet Home. The vast majority of tungsten particles collected from the powder drum and surface dust samples of Sweet Home were below $5 \mu \mathrm{m}$ in size (Figures $2(\mathrm{~g})$ $2(\mathrm{~h}))$. Median particle sizes were $\sim 1.50 \mu \mathrm{m}$ in both cases. In general, the size distributions of tungsten particles of these nonairborne samples are similar to the airborne samples of Sweet Home, illustrating that airborne tungsten particles collected with air filters accurately reflect the size distribution of tungsten particles at the industrial source. 


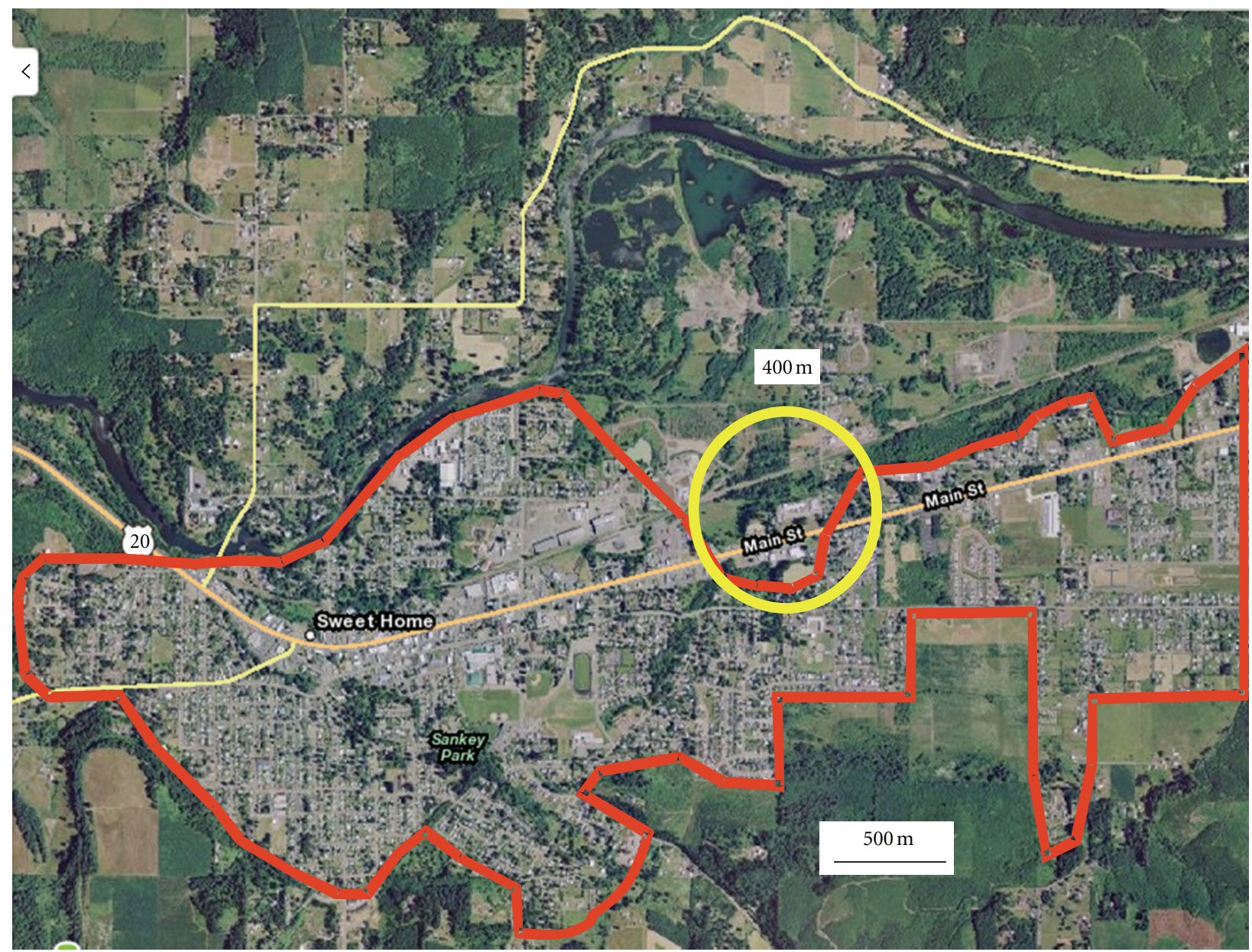

Figure 4: Aerial view of Sweet Home, Oregon, with the 400-m distance centered on the tungsten facility. The red boundary marks the limit of residential Sweet Home.

Maximum particle size from the drum sample was just over $50 \mu \mathrm{m}$ (Figure $2(\mathrm{~g})$ ), accurately reflecting the large target particle size of the manufacturer (personal communication with the facility manager). Maximum particle size from the surface dust sample was smaller (Figure 2(h)), just under $30 \mu \mathrm{m}$, accurately reflecting that large, dense airborne particles do not travel as far as smaller particles [26].

\subsection{Geographical Location of Tungsten Facilities Relative to} Their Towns. Fallon is relatively circular in layout, more or less centered on the crossroads of two highways (Figure 3). The hard metal facility of Fallon is located just northwest of the crossroads. Airborne tungsten loadings within $3 \mathrm{~km}$ of the hard metal facility can be elevated above loadings farther away that can be considered as background levels [9]. Most of residential Fallon is within $3 \mathrm{~km}$ of the hard metal facility, and much of Fallon is within $2 \mathrm{~km}$ of it. Thus, most Fallon residents potentially spend time daily within an environment of elevated levels of airborne tungsten.

Interestingly, urine samples of Fallon residents were significantly elevated in tungsten [27]. No linkage was concluded between elevated tungsten in Fallon residents and leukemia occurrence, in part because people from both the case and control populations showed elevated tungsten levels, dismissing tungsten as a discriminating factor for occurrence of leukemia. This inability to conclude linkage does not rule out linkage but rather reflects the difficulty of conclusively establishing linkage using the case-comparison study design [28].

In contrast to the roughly circular layout of Fallon, Sweet Home is relatively linear, stretching out along a single highway (Figure 4). The tungsten facility of Sweet Home is located just east of the center of town, on the northern side. Airborne tungsten loadings were elevated above background levels out to only $400 \mathrm{~m}$ away from the tungsten facility [20], a considerably shorter dispersal distance than the $3 \mathrm{~km}$ of Fallon. This could be explainable meteorologically: airborne heavy metals have been shown to correlate inversely with precipitation [29], and Sweet Home receives 10 times more rainfall than Fallon (Table 1). Little of residential Sweet Home lies within $400 \mathrm{~m}$ of the tungsten facility. Thus, few Sweet Home residents potentially spend time daily within an airborne environment with elevated levels of airborne tungsten. We know of no testing for tungsten in urine samples of Sweet Home residents to confirm exposure levels there. 


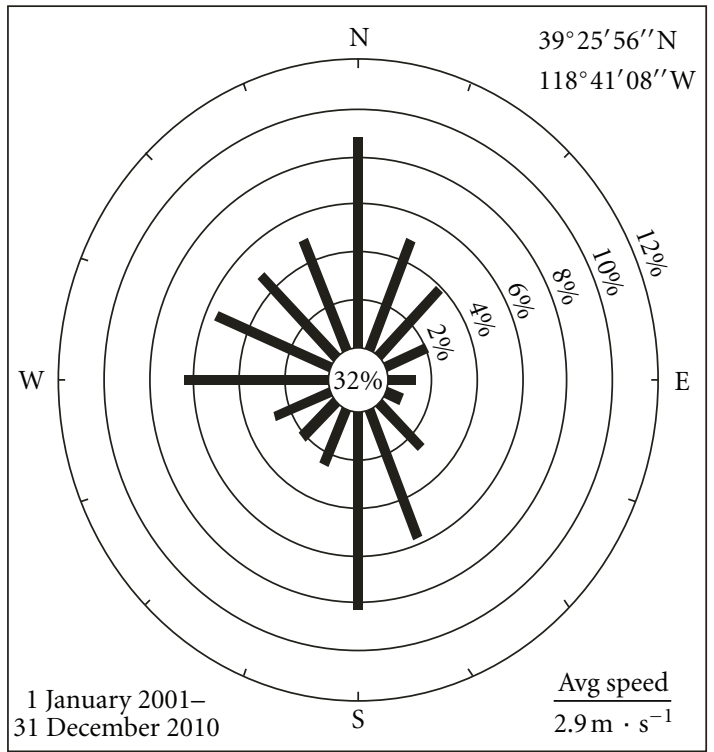

(a)

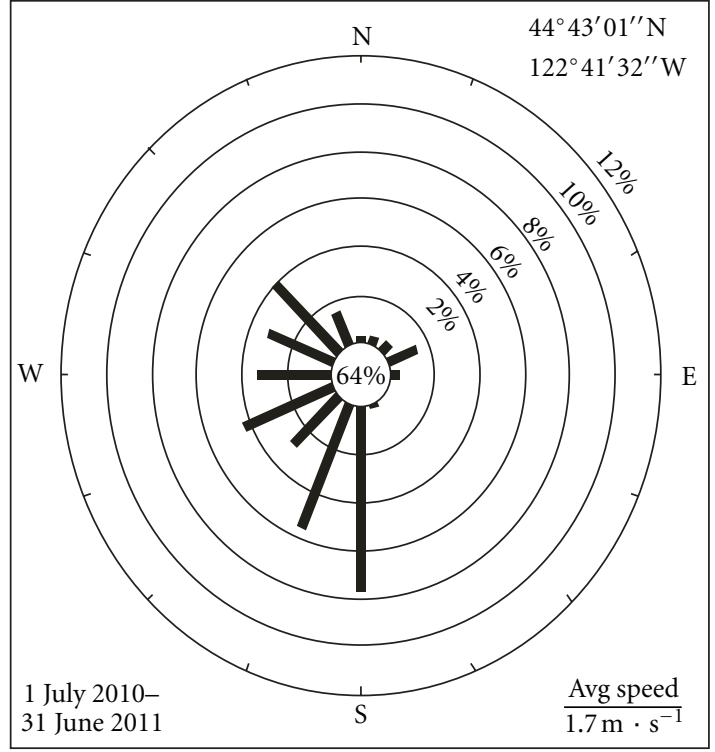

(b)

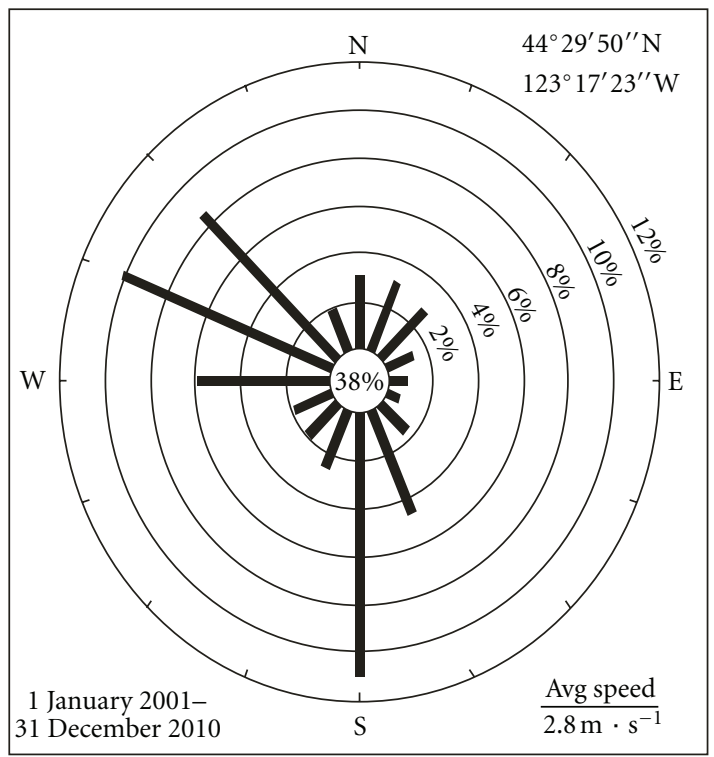

(c)

FIgURE 5: Wind rose diagrams for (a) Fallon, Nevada, a weather station with data for the entire decade of the 2000s, (b) Jordan, Oregon (Figure 1), a weather station with data for one year, and (c) Corvallis, Oregon (Figure 1), a weather station with data for the entire decade of the 2000s. Lines indicate directions that winds come from. Center percentages represent calm, that is, winds $\leq 2 \mathrm{~m} \cdot \mathrm{sec}^{-1}$. Time span and average wind speeds are given for each location. Wind data from NCDC, NOAA: wind roses generated using software of the Western Regional Climate Center.

3.4. Wind Patterns. Fallon typically experiences winds from the northeast, north, west, south, and southeast (Figure 5(a)). Given the central location of the hard metal facility in Fallon and these prevailing wind directions, much, if not most, of residential Fallon is downwind of the hard metal facility for at least some fraction of time at the annual scale. This should result in human exposure to elevated airborne tungsten levels for many, if not most, Fallon residents.

Sweet Home typically experiences winds from the northwest, west, southwest, and south (Figure 5(b)), or from the northwest and south (Figure 5(c)). Given the eastern location of the tungsten facility in Sweet Home and these prevailing wind directions, little of residential Sweet Home is downwind of the tungsten facility. This should result in little human exposure to elevated tungsten levels for Sweet Home residents.

\section{Conclusions}

As we have stated in prior work, it cannot be concluded from environmental data alone that elevated airborne tungsten 
causes childhood leukemia [9-13]. Such linkage requires direct biomedical research, which is at least supportable by the cooccurrence of exposure to airborne tungsten and a cluster of childhood leukemia $[28,30]$. Tungsten has been evaluated for carcinogenicity, by itself $[31,32]$ as well as with other metals [33-36]. In general, this biomedical research has shown at least the possibility of linkage between exposure to tungsten and cancer.

Regardless of the toxicity of tungsten, this comparison of airborne tungsten and geography between Fallon and Sweet Home does lead to the following conclusion: the lack of excessive cancer in Sweet Home, which has an industrial tungsten facility as well as elevated levels of airborne tungsten, cannot logically be used to dismiss the possibility of airborne tungsten as a factor in the cluster of childhood leukemia in Fallon, which also has an industrial tungsten facility as well as elevated levels of airborne tungsten. The size distributions of airborne tungsten in each town are similar, but the relative sizes and locations of the tungsten facilities differ between Fallon and Sweet Home as do prevailing wind directions and annual precipitation amounts such that human exposure to airborne tungsten is probably higher in Fallon than in Sweet Home. Additional modeling of all variables affecting airborne loadings of heavy metals would be needed to legitimately compare human exposures to airborne tungsten in Fallon and Sweet Home. In any case, continued biomedical research on possible linkage of tungsten with leukemia is justified based on the cooccurrence of elevated airborne tungsten and a cluster of childhood leukemia in Fallon, Nevada.

\section{Disclosure}

P. R. Sheppard and M. L. Witten have provided documents, data, and declarations in Cases CV03-03482, Richard Jernee et al. versus Kinder Morgan Energy et al., and CV03-05326, Floyd Sands et al. versus Kinder Morgan Energy et al., Second Judicial District Court of Nevada, Washoe County, which are related to the childhood leukemia cluster of Fallon. In these cases, the law firm of Dunlap and Laxalt, representing the plaintiffs, with full disclosure to all defendants and their counsels, made an unsolicited donation of $\$ 15,000$ to assist M. L.Witten and P. R. Sheppard in furthering their research, with a request that defendants provide similar donations. Neither M. L. Witten nor P. R. Sheppard have profited personally as a result of doing their research in Fallon or from providing material in these cases. B. J. Bierman and K. Rhodes declare that they have no conflict of interests.

\section{Acknowledgments}

Volunteer participants of Fallon and Sweet Home are acknowledged for allowing air sampling in their backyards. Robert J. Speakman and Mark Borgstrom assisted in this research. The original air sampling research was funded in part by the Gerber Foundation and the Cancer Research and Prevention Foundation, neither of which is otherwise responsible for this paper.

\section{References}

[1] United States Census, 2000, http://www.census.gov/main/ www/cen2000.html.

[2] This is Reno, "Kennametal celebrates 60 years in Fallon," 2011, http://thisisreno.com/2011/03/kennametal-celebrates-60years-in-fallon.

[3] Expert Panel, "Final report and recommendations to the Nevada State Health Division," Expert Panel on Childhood Leukemia in Churchill County, 2004, health.nv.gov/ PDFs/FALLONexpertpanel022304.pdf.

[4] Nevada State Health Division, "New childhood leukemia case confirmed," News Release, 2004.

[5] F. X. Mullen, "Metal remains at heart of fallon leukemia inquiry," Reno Gazette-Journal, 2010.

[6] Lahontan Valley News, "Obituary: Halycon Marie bice," 2010.

[7] U.S. NCI, Age-Adjusted SEER Incidence and the U.S. Death Rates and 5-Year Relative Survival Rates by Primary Cancer Sites, Sex, and Time Period. SEER Cancer Statistics Review, 1975-2000, Table XXVII-3: Childhood Cancers, National Cancer Institute, 2003.

[8] C. Steinmaus, M. Lu, R. L. Todd, and A. H. Smith, "Probability estimates for the unique childhood leukemia cluster in Fallon, Nevada, and risks near other U.S. Military aviation facilities," Environmental Health Perspectives, vol. 112, no. 6, pp. 766-771, 2004.

[9] P. R. Sheppard, G. Ridenour, R. J. Speakman, and M. L. Witten, "Elevated tungsten and cobalt in airborne particulates in Fallon, Nevada: possible implications for the childhood leukemia cluster," Applied Geochemistry, vol. 21, no. 1, pp. 152-165, 2006.

[10] P. R. Sheppard, R. J. Speakman, G. Ridenour, and M. L. Witten, "Using lichen chemistry to assess airborne tungsten and cobalt in Fallon, Nevada," Environmental Monitoring and Assessment, vol. 130, no. 1-3, pp. 511-518, 2007.

[11] P. R. Sheppard, R. J. Speakman, G. Ridenour, M. D. Glascock, C. Farris, and M. L. Witten, "Spatial patterns of tungsten and cobalt in surface dust of Fallon, Nevada," Environmental Geochemistry and Health, vol. 29, no. 5, pp. 405-412, 2007.

[12] P. R. Sheppard, C. L. Hallman, G. Rldenour, and M. L. Witten, "Spatial patterns of tungsten and cobalt on leaf surfaces of trees in Fallon, Nevada," Land Contamination and Reclamation, vol. 17, no. 1, pp. 31-41, 2009.

[13] P. R. Sheppard, G. Ridenour, and M. L. Witten, "Multi-year assessment of airborne metals in Fallon, Nevada, based on leaf-surface chemistry," in Air Quality Monitoring, Assessment and Management, N. Mazzeo, Ed., pp. 329-344, InTech, Rijeka, Croatia, 2011.

[14] H. K. Stager and J. V. Tingley, Tungsten Deposits in Nevada, Bulletin 105, University of Nevada-Reno School of Mines, Nevada Bureau of Mines and Geology, Reno, Nev, USA, 1988.

[15] K. H. Johannesson, W. B. Lyons, E. Y. Graham, and K. A. Welch, "Oxyanion concentrations in Eastern Sierra Nevada Rivers-3. Boron, Molybdenum, Vanadium, and Tungsten," Aquatic Geochemistry, vol. 6, no. 1, pp. 19-46, 2000.

[16] R. L. Seiler, K. G. Stollenwerk, and J. R. Garbarino, "Factors controlling tungsten concentrations in ground water, Carson Desert, Nevada," Applied Geochemistry, vol. 20, no. 2, pp. 423441, 2005.

[17] P. M. Harris and D. S. C. Humphreys, "Tungsten: a review," Occasional Papers of the Institution of Mining and Metallurgy paper 2, Institution of Mining and Metallurgy, London, UK, 1983. 
[18] F. X. Mullen Jr., "No pollution controls in tungsten plant," Reno Gazette-Journal, 2003.

[19] P. R. Sheppard, P. Toepfer, E. Schumacher, K. Rhodes, G. Ridenour, and M. L. Witten, "Morphological and chemical characteristics of airborne tungsten particles of Fallon, Nevada," Microscopy and Microanalysis, vol. 13, no. 4, pp. 296-303, 2007.

[20] P. R. Sheppard, R. J. Speakman, C. Farris, and M. L. Witten, "Multiple environmental monitoring techniques for assessing spatial patterns of airborne tungsten," Environmental Science and Technology, vol. 41, no. 2, pp. 406-410, 2007.

[21] G. G. Eadie and D. E. Bernhardt, "Sampling and data reporting considerations for airborne particulate radioactivity," Tech. Rep. ORP/LV-76-9, Environmental Protection Agency, Office of Radiation Programs, Las Vegas, Nev, USA, 1976.

[22] K. W. Lee and R. Mukund, "Filter collection," in Aerosol Measurement: Principles, Techniques, and Applications, P. A. Baron and K. Willeke, Eds., pp. 197-228, Wiley, New York, NY, USA, 2nd edition, 2001.

[23] HI-Q Environmental Products Company, Air Sampling Equipment, Systems \& Accessories, HI-Q, San Diego, Calif, USA, 2003.

[24] M. T. Ny and B. K. Lee, "Size distribution of airborne particulate matter and associated metallic elements in an urban area of an industrial city in Korea," Aerosol and Air Quality Research, vol. 11, no. 6, pp. 643-653, 2011.

[25] F. P. Perera and A. K. Ahmed, Respirable Particles: Impact of Airborne Fine Particulates on Health and the Environment, Ballinger Publishing Company, Cambridge, Mass, USA, 1979.

[26] R. D. Cadle, The Measurement of Airborne Particles, Wiley, New York, NY, USA, 1975.

[27] C. S. Rubin, A. K. Holmes, M. G. Belson et al., "Investigating childhood leukemia in Churchill County, Nevada," Environmental Health Perspectives, vol. 115, no. 1, pp. 151-157, 2007.

[28] J. D. Pleil, J. Sobus, P. R. Sheppard, G. Ridenour, and M. L. Witten, "Strategies for evaluating the environment-public health interaction of long-term latency disease: the quandary of the inconclusive case-control study," Chemico-Biological Interactions. In press.

[29] K. H. Kim, D. S. Kim, and T. J. Lee, “The temporal variabilities in the concentrations of airborne lead and its relationship to aerosol behavior," Atmospheric Environment, vol. 31, no. 20, pp. 3449-3458, 1997.

[30] J. B. Nielsen and T. K. Jensen, "Environmental epidemiology," in Essentials of Medical Geology: Impacts of the Natural Environment on Public Health, O. Selinus et al., Ed., pp. 529-540, Elsevier, Amsterdam, The Netherlands, 2005.

[31] N. N. Sun, C. D. Fastje, S. S. Wong et al., "Dose-dependent transcriptome changes by metal ores on a human acute lymphoblastic leukemia cell line," Toxicology and Industrial Health, vol. 19, no. 7-10, pp. 157-163, 2003.

[32] C. D. Fastje, K. Le, N. N. Sun, S. S. Wong, P. R. Sheppard, and M. L. Witten, "Prenatal exposure of mice to tungstate is associated with decreased transcriptome-expression of the putative tumor suppressor gene, DMBT1: implications for childhood leukemia," Land Contamination and Reclamation, vol. 17, no. 1, pp. 169-178, 2009.

[33] A. C. Miller, S. Mog, L. McKinney et al., "Neoplastic transformation of human osteoblast cells to the tumorigenic phenotype by heavy metal-tungsten alloy particles: induction of genotoxic effects," Carcinogenesis, vol. 22, no. 1, pp. 115125, 2001.

[34] A. C. Miller, K. Brooks, J. Smith, and N. Page, "Effect of the military-relevant heavy metals, depleted uranium and heavy metal tungsten-alloy on gene expression in human liver carcinoma cells (HepG2)," Molecular and Cellular Biochemistry, vol. 255, no. 1-2, pp. 247-256, 2004.

[35] R. M. Harris, T. D. Williams, N. J. Hodges, and R. H. Waring, "Reactive oxygen species and oxidative DNA damage mediate the cytotoxicity of tungsten-nickel-cobalt alloys in vitro," Toxicology and Applied Pharmacology, vol. 250, no. 1, pp. 1928, 2011.

[36] R. Verma, X. Xu, M. K. Jaiswal et al., "In vitro profiling of epigenetic modifications underlying heavy metal toxicity of tungsten-alloy and its components," Toxicology and Applied Pharmacology, vol. 253, no. 3, pp. 178-187, 2011. 


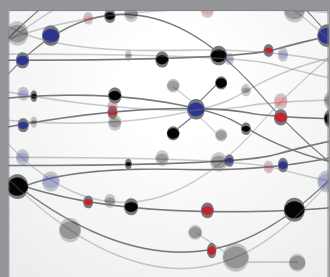

The Scientific World Journal
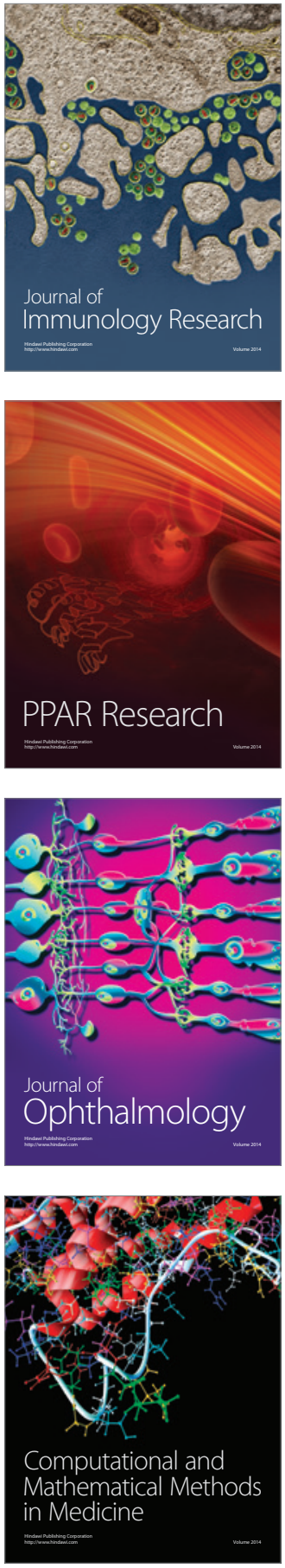

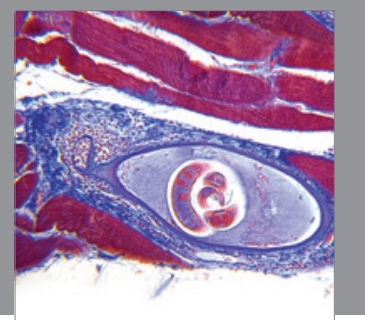

Gastroenterology

Research and Practice
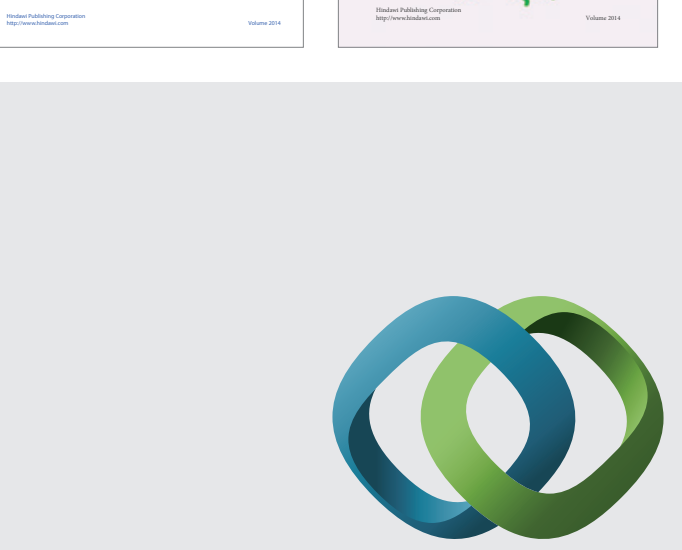

\section{Hindawi}

Submit your manuscripts at

http://www.hindawi.com
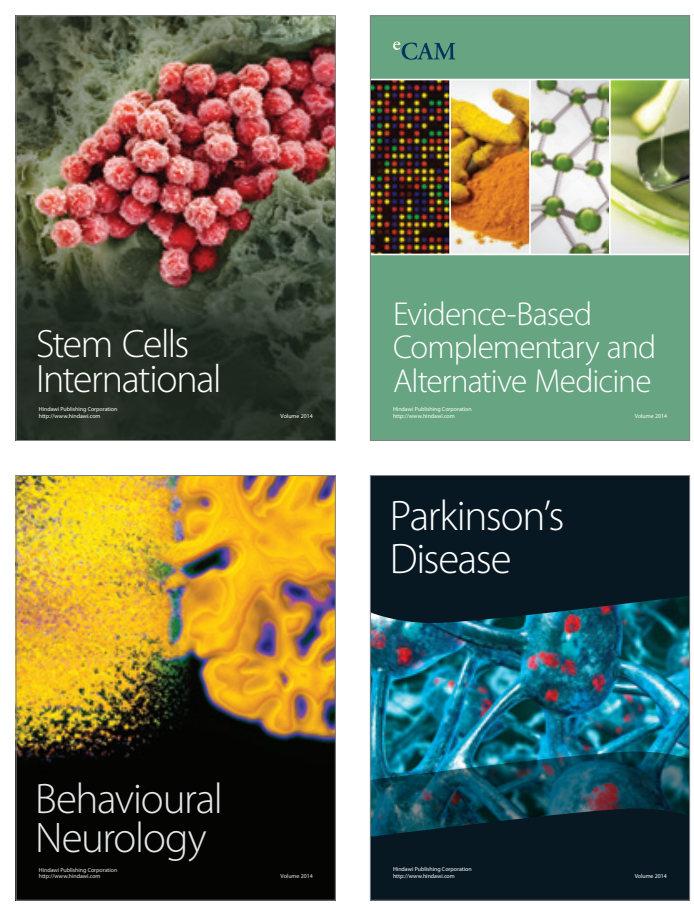

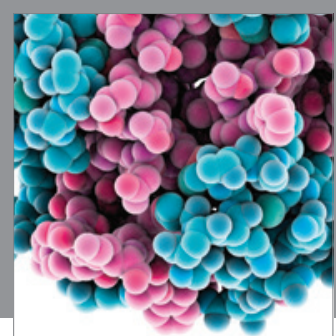

Journal of
Diabetes Research

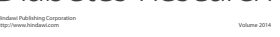

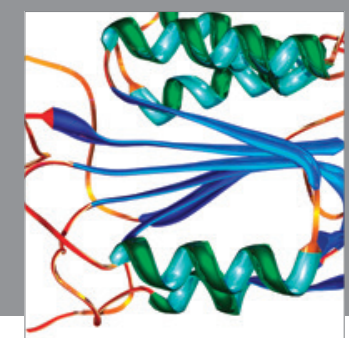

Disease Markers
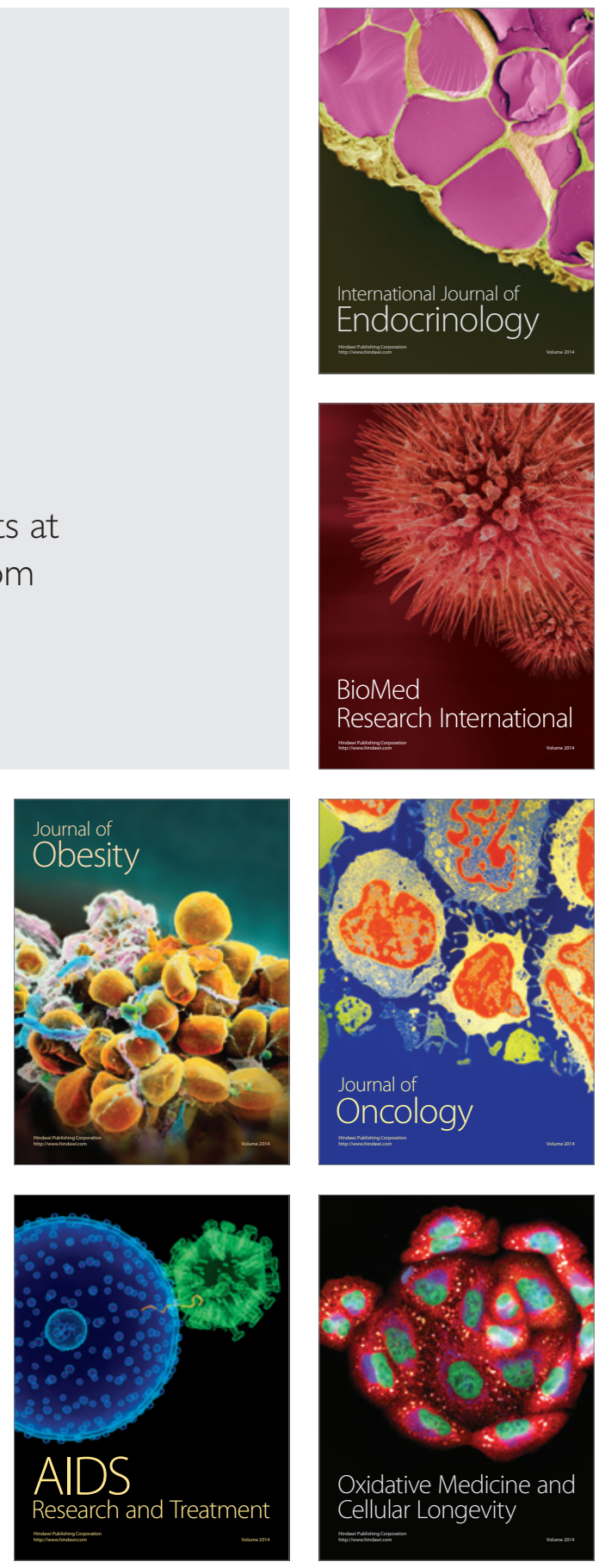